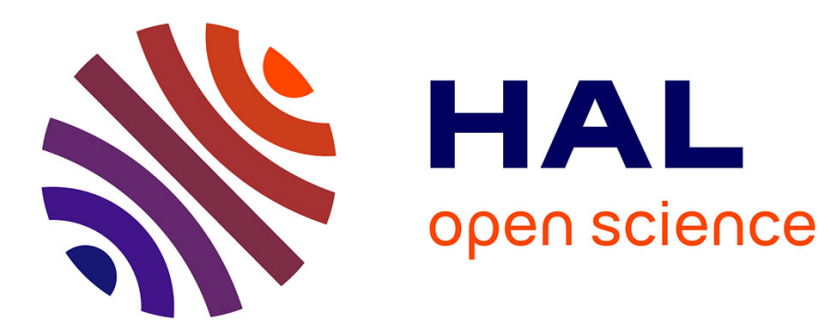

\title{
Role of obesity in differences in cervical cancer screening rates by migration history. The CONSTANCES survey
}

Cyrielle Crampe-Casnabet, Jeanna-Eve Franck, Virginie Ringa, Mireille Coeuret-Pellicer, Pierre Chauvin, Gwenn Menvielle

\section{- To cite this version:}

Cyrielle Crampe-Casnabet, Jeanna-Eve Franck, Virginie Ringa, Mireille Coeuret-Pellicer, Pierre Chauvin, et al.. Role of obesity in differences in cervical cancer screening rates by migration history. The CONSTANCES survey. Cancer Epidemiology, Biomarkers and Prevention, 2019, 58, pp.98-103. 10.1016/j.canep.2018.11.009 . hal-01980158

\section{HAL Id: hal-01980158 https: / hal.sorbonne-universite.fr/hal-01980158}

Submitted on 14 Jan 2019

HAL is a multi-disciplinary open access archive for the deposit and dissemination of scientific research documents, whether they are published or not. The documents may come from teaching and research institutions in France or abroad, or from public or private research centers.
L'archive ouverte pluridisciplinaire HAL, est destinée au dépôt et à la diffusion de documents scientifiques de niveau recherche, publiés ou non, émanant des établissements d'enseignement et de recherche français ou étrangers, des laboratoires publics ou privés. 


\section{Role of Obesity in Differences in Cervical Cancer Screening Rates by Migration History.}

\section{The CONSTANCES Survey}

Cyrielle Crampe-Casnabet ${ }^{1}$, Jeanna-eve Franck ${ }^{1}$, Virginie Ringa ${ }^{2}$, Mireille Coeuret-Pellicer $^{3,4}$, Pierre Chauvin ${ }^{1}$, Gwenn Menvielle ${ }^{1}$

1 INSERM, Sorbonne Université, Institut Pierre Louis d'Epidémiologie et de Santé Publique IPLESP, Department of social epidemiology, F75012 Paris, France

2 CESP, INSERM U1018, Univ Paris-Saclay, Univ Paris-Sud, UVSQ, Villejuif, France

3 Inserm, Population-based Epidemiologic Cohorts Unit, UMS 011, Villejuif, France

4 University of Versailles St-Quentin, UMRS 1018, Villejuif, France

Cyrielle Crampe-Casnabet : c.crampecasnabet@free.fr

Jeanna-eve Franck : jeanna-eve.franck@inserm.fr

Pierre Chauvin : pierre.chauvin@inserm.fr

Gwenn Menvielle : gwenn.menvielle@ inserm.fr - corresponding author

Inserm U1136 - ERES, 27 rue Chaligny, 75012 Paris, France

Virginie Ringa : virginie.ringa@inserm.fr

CESP - Hôpital Paul Brousse - Bâtiment 15-16 - 16 Avenue Paul Vaillant Couturier - 94807 Villejuif Cedex

Mireille Pellicer : mireille.pellicer@inserm.fr

UMS 11 Cohortes épidémiologiques en population - Inserm UVSQ - Hôpital Paul Brousse Bâtiment 15-16 - 16 Avenue Paul Vaillant Couturier - 94807 Villejuif Cedex 


\section{Acknowledgements}

The authors thank the Inserm-Versailles Saint Quentin en Yvelines University "Epidemiological Population-Based Cohorts Unit" (UMS 11) who designed and is in charge of the Constances Cohort Study. They also thank the "Caisse nationale d'assurance maladie des travailleurs salaries" (CNAMTS) and the "Centres d'examens de santé" of the French Social Security which are collecting a large part of the data, as well as the "Caisse nationale d'assurance vieillesse", ClinSearch, Asqualab and Eurocell in charge of the data quality control.

\section{Funding}

This work was supported by a grant from the French Agency on Cancer (INCa) [grant number 2014-1-PL SHS-05].

The CONSTANCES Cohort Study was supported and funded by the Caisse nationale d'assurance maladie des travailleurs salariés (CNAMTS). It also received a financial support from the Ministry of Health, the Council of the Ile de France Region, and by the Cohorts TGIR IReSP-ISP INSERM (Ministère de la santé et des sports, Ministère délégué à la recherche, Institut national de la santé et de la recherche médicale, Institut national du cancer et Caisse nationale de solidarité pour l'autonomie). The Constances Cohort Study is an « Infrastructure nationale en Biologie et Santé » and benefits from a grant from ANR (ANR-11INBS-0002). Constances is also partly funded by MSD, AstraZeneca and Lundbeck.

\section{Keywords}

Cervical cancer screening; migration status; obesity; France

\section{Declaration of interest}

None 
Word count (highlights, abstract, main text): 3337 


\title{
Highlights
}

- Cervical cancer screening rates are lower among immigrant women

- Higher BMI among immigrant does not mediate this association

- Foreign origin potentiates the effect of obesity on cervical cancer screening

- Obese foreign women are at higher risk for not undergoing cervical cancer screening

\begin{abstract}
Background: Immigrant women often have lower cervical cancer screening (CCS) rates, tend to have a higher body mass index (BMI) and may be more vulnerable to BMI-related stigmatization. Our aim was to assess the role of BMI in differences in CCS rates by migration history.

Methods: Analyses were based on the 2012-2015 inclusion data $(n=27,226)$ for the population-based CONSTANCES cohort, including detailed, self-reported information on demographics and socioeconomic characteristics, migration history, health behaviours, health, and health care use. Measured BMI (underweight (<18.5), normal-weight (18.5-25), overweight (25-30), obese (>30)) was collected. Poisson regression models with robust variance were conducted to assess the contribution of BMI to differences in CCS rates by migration history, and analyses stratified by BMI were done. Multiple imputations were performed.

Results: The CCS rates ranged from 87\% among French-born women with two French parents to $86 \%$ among French-born women with at least one parent of foreign origin, $82 \%$ among naturalized immigrants and $74 \%$ among non-naturalized immigrants. After adjusting for covariates, non-naturalized immigrants showed an 11\% (95\% CI: 8\%-14\%) lower CCS rate than French-born women with two French parents. Adjusting for BMI did not change the estimates. When stratifying by BMI category, non-naturalized immigrants showed an $11 \%$
\end{abstract}


(7\%-14\%) lower CCS rate then French-born with two French parents when normal weight, a 9\% (2\%-16\%) lower CCS rate when overweight, and an 18\% (5\%-30\%) lower CCS rate when obese.

Conclusion: Migration history and BMI jointly impact CCS rates. They were lower among all non-naturalized immigrants, particularly those who were obese. 


\section{Introduction}

In France in 2015, 1092 women died from cervical cancer (mortality rate of 1.7 for 100000 women) and 2797 new cases were recorded (incidence rate of 5.9 for 100000 women).[1] Cervical cancer screening (CCS) permits the detection of precancerous lesions and helps reduce the incidence of this cancer and its mortality. In France, CCS is opportunistic, except in 11 out of the 96 French administrative departments, where organized screening is implemented. CCS is recommended for women aged 25 to 65 years and involves a Pap test performed every 3 years after two normal Pap test one year apart. According to administrative data, the CCS rate only reached $61 \%$ between 2010 and 2014,[2] which is far below the $80 \%$ objective set by French authorities.

Among the various demographic, socioeconomic, health behaviour-, health care use- and health care access-related factors,[3-5] migration status is strongly associated with CCS. Studies on CCS by migration status are scarce in France,[6] but the literature consistently reports lower CCS rates among women of foreign origin, regardless of the indicator considered, e.g., nationality, country of birth or parental geographical origins.[7-9] In addition, studies usually report a gradient between migration status and CCS rates: the highest CCS rate is observed among women born with the nationality of the country they live in, a lower rate is reported among naturalized women, and the lowest rate is observed among women of foreign nationality.[6, 10] As well, a French survey found that screening uptake was higher among French women both of whose parents were of French origin than among French women who had at least one parent of foreign origin.[6] Finally, the CCS rate increased with the level of acculturation,[10] and studies also report an increase in the CCS rate with the amount of time spent in the host country, which is an indirect measure of acculturation.[7, 9] 
The mechanisms responsible for the lower CCS uptake among women of foreign origin remain largely unexplained. Studies have shown that the lower socioeconomic status (SES) of women of foreign origin only partly accounts for their lower CCS rate.[6-8, 10] To our knowledge, the role of BMI in the lower CCS rate among women of foreign origin has so far not been investigated. BMI may contribute to the association between migration status and CCS in several ways. Indeed, higher BMIs have been reported among women of foreign origin in several European countries,[11-13] including France,[14] and lower CCS rates are consistently observed among overweight and obese women than among normal-weight women.[15] The lower CCS uptake among women of foreign origin might then be partially explained by a higher rate of overweight and obesity in these groups and BMI might be a mediator in the association between migration status and CCS.

It is also possible that differences in participation in CCS according to migration status might be more pronounced among overweight and obese women than among women with lower BMI. Indeed, different explanations have been proposed to explain why obese women delay CCS, such as poor self-esteem and body image, embarrassment, fear of pain, a perceived lack of respect from health-care providers, and avoidance of unwanted weight loss advice.[15] These mechanisms may be more pronounced among foreign women, who constitute an especially vulnerable group due to their poor socioeconomic situation, their unfamiliarity with the health-care system, their low health insurance coverage, and their having experienced discrimination due to their foreign origin.[16, 17]

The aim of our study, which uses data from a large population-based survey, was to assess the role of BMI in differences in CCS rates by migration status. 


\section{Material and Methods}

CONSTANCES is a French cohort designed as an age-, gender- and socioeconomic statusrepresentative sample of adults aged 18-69 associated with the National Health Insurance Fund (CNAMTS). The procedures for inclusion, data collection and data management have been described elsewhere.[18] Randomly selected eligible persons were invited to go to one of the 22 health screening centres administered by the National Health Insurance Fund. A large number of socioeconomic, demographic and health-related data were collected from the volunteers at inclusion through self-administered questionnaires, face-to-face interviews and medical examinations performed at the health screening centers. The study population included women recruited in CONSTANCES from January 2012 to December 2015.

Self-declared participation in CCS was used as the dependent variable. According to French recommendations, women aged 25-65 who have had a Pap test during the past 3 years were considered up-to-date with CCS. Official exclusion criteria were applied.[19] In all, 31,024 women were included in the analyses.

Four migration status groups were created based on the women's nationality and their parents' geographical area of origin: French-born women with two parents of French origin (main group), French-born women with at least one parent of foreign origin, naturalized women, and women of foreign nationality. Measured size and weight were used to create a BMI variable: underweight $\left(\mathrm{BMI}<18.5 \mathrm{~kg} / \mathrm{m}^{2}\right)$, normal weight $\left(18.5 \leq \mathrm{BMI}<25 \mathrm{~kg} / \mathrm{m}^{2}\right)$, overweight $(25 \leq$ BMI $<30 \mathrm{~kg} / \mathrm{m}^{2}$ ) and obese $\left(\mathrm{BMI} \geq 30 \mathrm{~kg} / \mathrm{m}^{2}\right)$. The following characteristics were used as confounding factors (categories are presented in table 1): age, having a partner, area of residence, employment status, educational level, having experienced financial difficulties, having refrained from seeking health care for financial reasons in the past year, depressive 
disorder, self-reported health, alcohol consumption, smoking status, and gynaecological follow-up (use of a prescription drug for a gynaecological condition).

Pairwise correlation was assessed between the confounding variables with Cramer's V to avoid multi-colinearity in multivariate models. CCS rates were computed according to demographic, socioeconomic, health and health-care use characteristics. Robust Poisson regression models were conducted to obtain prevalence ratios (PR) and their 95 percent confidence intervals (CIs).[20, 21] Confounding variables associated with CCS in age- and migration status-adjusted analyses $(p<0.20)$ were included in the multivariate regression models. Only the confounding variables, which were still associated with the dependent variable at the 5\% level using backward selection, were kept in the final model.

In a first step, the role of BMI as a mediator of the association between migration status and CCS was assessed. The mediation analysis relies on four hypothesis: i) a significant association between the exposure and the outcome existed, ii) a significant association between the exposure and the mediator existed, iii) a significant association between the mediator and the outcome after adjusting for exposure existed, iv) after adjusting for the mediator, the association between the exposure and the outcome decreased, justifying that the mediator explained part of the relationship between the exposure and the outcome.[22] As these hypotheses were not verified (see Results section), the mediation analysis was not performed.

In a second step, analyses stratified by BMI were conducted to assess whether participation in CCS according to migration status differed by BMI group. Due to too small numbers, underweight women were grouped with the normal weight women. Finally, analyses to assess if women's geographical origin (Africa, other) impacted CCS among naturalised and foreign women were conducted. 
Missing data were imputed using multiple imputations by fully conditional specification. Fifty complete datasets were created. To make the MAR assumption more plausible, every previously described variable was used for the imputation model, $[23,24]$ including the outcome. In addition, waist size was introduced as a continuous auxiliary variable. Since the outcome variable contained missing values, sensitivity analyses were conducted, using the Multiple Imputations then Deletion method that enabled to take this missingness into account in the imputation model but not in the analyses.[25] Information on the last CCS date was missing for $12.2 \%$ of the sample, and migration status for $2.0 \%$. Overall, there were fewer than $5 \%$ missing data for all the explanatory variables, with the exception of BMI (7.0\%), gynaecological follow-up (6.4\%), alcohol consumption (7.0\%) and depressive disorder $(5.6 \%)$. SAS $9.4 ®$ was used to perform the analyses. 


\section{Results}

The distribution and the CCS rates for every women's characteristic are presented in Table 1. Naturalized women and women of foreign nationality accounted for $4.7 \%$ and $3.8 \%$ of the 31,024 women in our sample, respectively. Overweight and obese women accounted for $22.9 \%$ and $11.3 \%$ of the sample, respectively. French-born women (main group) had the highest screening rate $(87.1 \%)$, followed by French-born women with at least one foreign parent $(85.7 \%)$, naturalized women $(82.0 \%)$ and women of foreign nationality $(73.8 \%)$. The CCS rate increased from $77.5 \%$ among obese women to $85.0 \%$ among overweight women, $88.1 \%$ among normal-weight women and $88.6 \%$ among underweight women. Overweight and obesity were more frequent among the naturalized women and women of foreign nationality than among French-born women (Table 2).

After adjusting for the covariates, the CCS rates were similar among all French-born women, regardless of their parents' origin. Women of foreign nationality had an $11 \%$ lower CCS rate (95\% CI: 8\%-14\%) than women in the main group. Naturalized women had a $2 \%$ lower screening rate, but this result did not achieve statistical significance (Table 3). After adjusting for the covariates, BMI was strongly associated with CCS (underweight PR=1.02 [95\% CI: 0.99-1.04]; overweight 0.98 [0.97-0.99]; obese 0.91 [0.90-0.93]) but adjustment for BMI did not modify the estimates of the association between migration status and CCS (table 3). One of the underlying hypotheses of mediation model was not verified, therefore BMI was not a mediator of the association between migration origin and CCS.

The interaction term between migration status and BMI did not reach statistical significance ( $p=0.236$ ), but it was significant when both BMI and migration status were considered in two groups (obese/non-obese and French/foreign nationality, $p=0.014$ ). When stratifying by BMI 
category, after adjustment for the covariates, non-naturalized immigrants showed an $11 \%$ (7\%-14\%) lower CCS rate than French-born with two French parents when normal weight, a 9\% (2\%-16\%) lower CCS rate when overweight, and an 18\% (5\%-30\%) lower CCS rate when obese. In contrast, the CCS rates among French-born women with parents of foreign origin were similar to those among the women in the main group in all BMI categories. No clear pattern was observed for naturalized immigrant women, and the estimates did not achieve statistical significance.

Additional analyses accounting for women's origin were performed. After adjusting for covariates, African origin was associated with lower CCS rate among naturalized and foreign women, but this result was significant only among foreigners. Foreign women with African origin had an $18 \%$ lower CCS rate (95\% CI: 8\%-26\%) and foreign women with another origin a $10 \%$ lower CCS rate (6\%-13\%) than women in the main group (Additional table). When stratifying by BMI, after adjusting for covariates, there was no significant difference among naturalised women regardless of their origin. Among foreigners however, CCS rate was lower for women with African origin than for women with another origin in all BMI groups, and was especially pronounced among obese. This difference reached statistical significance only in the under- and normal-weight group (Additional table). These analyses were nevertheless based on small numbers. 


\section{Discussion}

We investigated the role of BMI in CCS differences by migration status. We observed a lower CCS rate among women of foreign nationality. The difference was more pronounced among obese (18\%) than among normal-weight or overweight women (9\% and $11 \%)$.

We observed lower CCS rate among women of foreign origin, which is consistent with the literature, and we found that the more belonging to the host country was important, the more the CCS rate was closer to what it was in the main group.[6, 7, 9, 10, 36] Studies have reported differences in CCS rates according to the women's country of birth. A Spanish study reported that the lower CCS rates observed were limited to women born in low-income countries,[8] but a US study found more contrasted results. They observed lower CCS rates among all women born abroad, but only women from Asia and India stood out with much lower CCS rates.[9] This heterogeneity in CCS rate among women of foreign origin was observed in our data, where CCS rates were lower among naturalised and foreign women of African origin than of another origin.

The association between CCS and migration status was not explained away by the range of confounding factors included in our model, one of which was a detailed measure of SES. We could not account for important factors that could be more prevalent among women of foreign origin and that might account for their having the lowest CCS rate, namely a lack of or incomplete health insurance, unfamiliarity with the health-care system and/or with CCS, poor health literacy, linguistic barriers, having experienced migration-related discrimination, and different socioculturally based health beliefs and attitudes towards medical care, as well as low levels of trust in doctors and the health-care system.[8, 16, 17, 37-39] In addition, we 
used a crude measure to account for gynaecological follow-up, a major determinant of CCS, and residual confounding is therefore likely to remain.

Our study participates in the elucidation of the role of BMI in the association between migration status and CCS. We found that BMI did not contribute to the association between migration origin and CCS, with identical estimators when this characteristic was or was not included in the regression model. Differences in the distribution of BMI according to migration status might not be large enough to explain participation in CCS. Indeed, migrant women form a heterogeneous group with respect to BMI.[11] [12] For instance, a Swedish study reported higher obesity rates among all migrant women than among women who were native of the host country, but the rates were especially high among those from Arabicspeaking countries and Poland.[11] This heterogeneity was also reported in a French study conducted in the Paris region, where, compared to women with two French parents, higher overweight and obesity rates were found only among women from Northern and Sub-Saharan Africa but not among women from other countries or those with one foreign parent.[14] Our findings are consistent with this French survey. However, women of African origin accounted for only $1.3 \%$ (naturalized) and $0.7 \%$ (foreigner) of the women included in our sample, which could explain why BMI did not contribute to the association between migration status and CCS among all the women in our data.

Association between migration status and CSS was more pronounced among obese than among normal-weight or overweight women. Obesity seemed to potentiate the lack of participation in CCS among the women of foreign nationality. Discrimination and the health care provider-woman relationship may explain this finding. First, obese migrant women face double discrimination in access to care and CCS because of their high BMI and their migrant 
origin. This double discrimination may potentiate the effects of each type of discrimination, in particular, because this group is also more vulnerable due to its low SES. Second, woman's satisfaction with and adherence to medical recommendations are closely linked to the health care provider-patient communication and interaction. Obese women report a perceived lack of respect from health care providers regarding their weight and associated health behaviours or want to avoid unwanted weight loss advice, both of which are barriers to CCS.[15] Furthermore health care providers report technical difficulties and reluctance in performing pelvic examination and Pap tests on obese women. Migrant women report low levels of trust in physicians and the health-care system, which is partly due to sociocultural discordance between the physician and patient.[16, 17, 40] As for discrimination in care, these two factors could negatively affect each other and account for the extremely low CCS rate reported among obese migrant women.

The CONSTANCES survey has several strengths, namely, the large sample size, the diversity of the collected data, which enabled us to account for a large range of CCS determinants, and the measured height and weight, which avoided the well-known bias for self-reported BMI.[26] However, while the percentage of missing values for each variable was low and below $5 \%$ for most of variables, we lost approximately $40 \%$ of the sample when limiting the analysis to the complete-case sample. We therefore used multiple imputations to address the missing values. We used two different methods that accounted differently for the missing values for the outcome and obtained similar results (not shown).

Some limitations must be discussed. First, we defined migration status on the basis of the woman's nationality and her parents' geographical origin. The latter is an indirect and inexact measure of the nationality at birth and may therefore result in some misclassifications. 
Second, although close to those observed in other French health surveys, [27, 28] the CCS rate in our sample (86.1\%) was higher than that observed in administrative data (61\%)[2]. Such substantial overreporting is common.[29, 30] In addition to desirability bias, this overreporting is probably due, in part, to the fact that some women equate any examination of the pelvic area to a Pap test.[30] In addition to misreporting, there is the issue of nonreporting. There were $12.2 \%$ missing data for the outcome variable. This could be explained by the question that asked for the month and year of the last Pap test. SES does not seem to be strongly associated with error in self-reporting,[30] although some studies report greater misreporting among lower SES women.[31].

Third, participation bias is always an issue in population-based surveys. With regard to the main variables of interest in our study (migration status and BMI), the women in our sample had a lower obesity rate than the general French female population $(11.3 \%$ vs. $16.7 \%$ in the French reference study on obesity and overweight). However, they had a similar rate of overweight (22.9\% vs. 25.2\%).[32] Despite the previously discussed limits of the migration origin variable, the proportion of French-born women with at least one parent of foreign origin and of naturalized women were close to that observed in the general French population (11.5\% in our data vs $11.0 \%$ of people born in France (2015) and $4.7 \%$ in our data vs $5.0 \%$ of people of French nationality (2009), respectively).[33, 34] On the contrary, women of foreign nationality were underrepresented in our sample: $3.8 \%$ vs. $6.4 \%$ of the population in France (2014).[35] In our data, when compared with the general population, women of European origin were over-represented, while women of African origin were under-represented, both among naturalised and foreign women. For instance, $20 \%$ of foreign women were of African origin in our data compared to $40 \%$ in the general population in France.[34] As women of African origin both participated less in the survey and are more frequently obese than women 
of other foreign origin, the distribution of BMI according to migration status might be smoothed and mediation or interaction effect might be hidden.

In conclusion, we found that migration history and BMI jointly impact CCS rates. These rates are lower among all non-naturalized immigrant women, especially among those who are obese. Obese women of foreign nationality therefore seem to be disproportionately at risk for not undergoing CCS. To better understand the mechanisms at work, there is a need for studies focusing on specific groups of migrant women. 
Table 1: Distribution and cervical cancer screening (CCS) rate according to the women's characteristics - Results pooled from 50 imputed datasets $(\mathrm{N}=31,024)$

\begin{tabular}{|c|c|c|c|c|c|}
\hline & $\%$ & $\begin{array}{l}\text { CCS } \\
\text { rate } \\
(\%)\end{array}$ & & $\%$ & $\begin{array}{l}\text { CCS } \\
\text { rate } \\
(\%)\end{array}$ \\
\hline Migration status*** & & & BMI category**** & & \\
\hline French with two French parents & 80.1 & 87.1 & Underweight & 3.8 & 88.6 \\
\hline $\begin{array}{l}\text { French with at least one foreign } \\
\text { parent }\end{array}$ & 11.5 & 85.7 & Normal weight & 62,0 & 88.1 \\
\hline Naturalized women & 4.7 & 82.0 & Overweight & 22.9 & 85.0 \\
\hline Foreign women & 3.8 & 73.8 & Obesity & 11.3 & 77.5 \\
\hline Employment status**** & & & Area of residence* & & \\
\hline Working & 74.9 & 87.8 & Rural & 16.6 & 85.5 \\
\hline Unemployed or job seeker & 7.2 & 80.7 & $<20000$ inhabitants & 13.6 & 85.6 \\
\hline Retired & 12.3 & 82.5 & $\begin{array}{l}\text { [20 000-100 000[ } \\
\text { inhabitants }\end{array}$ & 6.5 & 85.3 \\
\hline Inactive or student & 5.6 & 80.2 & $\geq 100000$ inhabitants & 44.6 & 86.8 \\
\hline Educational level*** & & & Paris area & 18.6 & 86.1 \\
\hline No diploma or Primary education & 8.6 & 77.9 & $\begin{array}{l}\text { Gynecological follow- } \\
\text { up }^{* * *}\end{array}$ & & \\
\hline Vocational secondary & 13.7 & 84.4 & No & 55.6 & 82.3 \\
\hline High school & 16.8 & 86,0 & Yes & 44.4 & 91,0 \\
\hline Bachelor degree & 39.5 & 87.8 & Smoking status*** & & \\
\hline Master degree or more & 21.5 & 87.8 & Never-smoker & 49.4 & 85.8 \\
\hline Economic difficulties $* * *$ & & & Smoker & 19.8 & 84.4 \\
\hline
\end{tabular}




\begin{tabular}{|c|c|c|c|c|c|}
\hline Never & 59.2 & 88.1 & Ex-smoker & 30.8 & 87.9 \\
\hline Occured in the past & 26.2 & 84.7 & Alcohol consumption ${ }^{1} * * *$ & & \\
\hline Since less than a year & 7.8 & 82.6 & Abstinent & 6,0 & 75.2 \\
\hline Since more than a year & 6.8 & 79.6 & Nor abuse nor dependence & 77.5 & 87.0 \\
\hline Healthcare renouncement $* * *$ & & & Abuse & 13.6 & 87.6 \\
\hline No & 83.2 & 87.5 & Dependence & 2.9 & 79.4 \\
\hline Yes & 16.8 & 79.9 & Depressive disorder ${ }^{2} * * *$ & & \\
\hline $\operatorname{Age}^{* * *}$ & & & No & 71.9 & 87.4 \\
\hline $25-34$ & 19.2 & 84.4 & Yes & 28.1 & 83.1 \\
\hline $35-44$ & 24.9 & 88.2 & Self reported health*** & & \\
\hline $45-54$ & 27.3 & 88.8 & Very good & 47.9 & 88.4 \\
\hline $55-65$ & 28.6 & 83.2 & Good & 29.8 & 86.1 \\
\hline Having a partner*** & & & Middling & 18.3 & 82.2 \\
\hline No & 19.3 & 80.5 & Poor & 3.3 & 79.1 \\
\hline Yes & 80.7 & 87.5 & Bad to very bad & 0.7 & 79.4 \\
\hline
\end{tabular}

1: AUDIT-C scale

2: CES-D depression scale using the validated French cut-off

BMI: body mass index

$* \mathrm{p}=0.1 * * * \mathrm{p}<0.001$ (Combined type III analyses) 
Table 2: Distribution of BMI categories according to migration status - Results pooled from 50 imputed datasets $(\mathrm{N}=31,024)$

\begin{tabular}{|c|c|c|c|c|}
\hline \multirow[b]{2}{*}{ Migration status } & \multicolumn{4}{|c|}{ BMI category (\%) } \\
\hline & Underweight & Norma & Overweight & Obesity \\
\hline French with two French parents & 3.8 & 62.9 & 22.4 & 10.9 \\
\hline $\begin{array}{l}\text { French with at least one foreign } \\
\text { parent }\end{array}$ & 3.9 & 60,0 & 23.8 & 12.3 \\
\hline Naturalized immigrant... & 2.5 & 55.3 & 26.8 & 15.4 \\
\hline $\begin{array}{l}\text {... of African origin* } \\
\text {...of other origin* }\end{array}$ & $\begin{array}{l}43.2 \\
64.2\end{array}$ & & $\begin{array}{l}34.5 \\
23.7\end{array}$ & $\begin{array}{l}22.3 \\
12.1\end{array}$ \\
\hline Foreign immigrant... & 5.2 & 57.9 & 24.4 & 12.5 \\
\hline $\begin{array}{l}\text {...of African origin* } \\
\text {...of other origin* }\end{array}$ & $\begin{array}{l}37.1 \\
69.9\end{array}$ & & $\begin{array}{l}36.0 \\
21.4\end{array}$ & $\begin{array}{l}26.9 \\
8.7\end{array}$ \\
\hline
\end{tabular}

BMI: body mass index

* Due to too small numbers, underweight and normal weight women were grouped 
Table 3: Cervical cancer screening (CCS) rate and Prevalence Ratios (PRs) for participation in CCS by migration status among all the women and by BMI category - Results pooled from 50 imputed datasets $(\mathrm{N}=31,024)$

\begin{tabular}{|c|c|c|c|}
\hline Age- & & Multivariate & Multivariate \\
\hline adjusted & Age-adjusted model & model* with & model* without \\
\hline CCS rate & & BMI & BMI \\
\hline
\end{tabular}

$\begin{array}{lllllll}\% & \text { PR } & 95 \% \mathrm{Cl} & \mathrm{PR} & 95 \% \mathrm{Cl} & \mathrm{PR} & 95 \% \mathrm{Cl}\end{array}$

\section{Among all women}

French-born with two French

$\begin{array}{llll}87.1 & 1.00 & 1.00 & 1.00\end{array}$

parents

French-born with at least one

$85.7 \quad 0.98[0.97-1.00] 1.00[0.98-1.01] 1.00[0.98-1.01]$

foreign parent

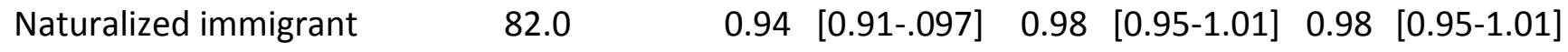

Women of foreign nationality $73.8 \quad 0.84 \quad[0.81-0.88] \quad 0.89 \quad[0.86-0.92] 0.89$ [0.86-0.92]

By BMI category

Underweight and normal

weight

French-born with two French

$\begin{array}{lll}88.7 & 1.00 & 1.00\end{array}$

parents

French-born with at least one

$88.0 \quad 0.99[0.97-1.01] 1.00[0.98-1.02]$

foreign parent

Naturalized immigrant

85.3

$0.96[0.93-0.99] \quad 0.98 \quad[0.95-1.01]$

Women of foreign nationality

76.9

$0.86 \quad[0.83-0.90] \quad 0.89 \quad[0.86-0.93]$ 


\section{Overweight}

French-born with two French
86.2
1.00
1.00

parents

French-born with at least one

$84.5 \quad 0.98 \quad[0.95-1.01] \quad 0.99 \quad[0.96-1.03]$

foreign parent

Naturalized immigrant

78.0

$0.9 \quad[0.85-0.95] \quad 0.95 \quad[0.90-1.01]$

Women of foreign nationality $\quad 73.0$

$0.84 \quad[0.78-0.91] \quad 0.91 \quad[0.84-0.98]$

\section{Obesity}

French-born with two French

$\begin{array}{lll}78.6 & 1.00 & 1.00\end{array}$

parents

French-born with at least one

$76.5 \quad 0.97 \quad[0.91-1.03] \quad 1.00[0.94-1.06]$

foreign parent

Naturalized immigrant

76.6

$0.97 \quad[0.89-1.06] 1.03 \quad[0.93-1.13]$

Women of foreign nationality

59.9

$0.75[0.65-0.87] \quad 0.82 \quad[0.70-0.95]$

BMI: body mass index

* The model was adjusted for the following covariates: age, having a partner, area of residence, employment status, educational level, having experienced financial difficulties, forgoing of health care for financial reasons, self-reported health, alcohol consumption, smoking status, and gynaecological follow-up. 
1. INCa, Les cancers en France en 2015. 2016: Boulogne-Billancourt.

2. Barré S, Massetti M, Leleu H, Catajar N, and de Bels F (2017) [Characteristics of french women who fail to undergo regular Pap smears for cervical cancer screening] [French]. BEH 39: $39-47$

3. Sicsic J and Franc C (2014) Obstacles to the uptake of breast, cervical, and colorectal cancer screenings: what remains to be achieved by French national programmes? BMC Health Serv Res 14: 465 10.1186/1472-6963-14-465.

4. Ricardo-Rodrigues I, Jimenez-Garcia R, Hernandez-Barrera V, Carrasco-Garrido P, JimenezTrujillo I, and Lopez de Andres A (2015) Social disparities in access to breast and cervical cancer screening by women living in Spain. Public Health 129: 881-8 10.1016/j.puhe.2015.02.021.

5. Menvielle G, Richard JB, Ringa V, Dray-Spira R, and Beck F (2014) To what extent is women's economic situation associated with cancer screening uptake when nationwide screening exists? A study of breast and cervical cancer screening in France in 2010. Cancer Causes Control 25: 977-83 10.1007/s10552-014-0397-z.

6. Rondet C, Lapostolle A, Soler M, Grillo F, Parizot I, and Chauvin P (2014) Are immigrants and nationals born to immigrants at higher risk for delayed or no lifetime breast and cervical cancer screening? The results from a population-based survey in Paris metropolitan area in 2010. PLoS One 9: e87046 10.1371/journal.pone.0087046.

7. De Alba I, Hubbell FA, McMullin JM, Sweningson JM, and Saitz R (2005) Impact of U.S. citizenship status on cancer screening among immigrant women. J Gen Intern Med 20: 290-6 10.1111/j.1525-1497.2005.40158.x.

8. Pons-Vigues M, Puigpinos-Riera R, Rodriguez-Sanz M, Serral G, Palencia L, and Borrell C (2011) Preventive control of breast and cervical cancer in immigrant and native women in Spain: the role of country of origin and social class. Int J Health Serv 41: 483-99

9. Tsui J, Saraiya M, Thompson T, Dey A, and Richardson L (2007) Cervical cancer screening among foreign-born women by birthplace and duration in the United States. I Womens Health (Larchmt) 16: 1447-57 10.1089/jwh.2006.0279.

10. Echeverria SE and Carrasquillo O (2006) The roles of citizenship status, acculturation, and health insurance in breast and cervical cancer screening among immigrant women. Med Care 44: 788-92 10.1097/01.mlr.0000215863.24214.41.

11. Lindstrom M and Sundquist K (2005) The impact of country of birth and time in Sweden on overweight and obesity: a population-based study. Scand J Public Health 33: 276-84 10.1080/14034940510005653.

12. Smith NR, Kelly YJ, and Nazroo JY (2012) The effects of acculturation on obesity rates in ethnic minorities in England: evidence from the Health Survey for England. Eur J Public Health 22: 508-13 10.1093/eurpub/ckr070.

13. Agyemang C, Kunst A, Bhopal R, et al (2011) Dutch versus English advantage in the epidemic of central and generalised obesity is not shared by ethnic minority groups: comparative secondary analysis of cross-sectional data. Int J Obes (Lond) 35: 1334-46 10.1038/ijo.2010.281.

14. Martin-Fernandez J, Grillo F, Tichit C, Parizot I, and Chauvin P (2012) Overweight according to geographical origin and time spent in France: a cross sectional study in the Paris metropolitan area. BMC Public Health 12: 937 10.1186/1471-2458-12-937.

15. Maruthur NM, Bolen SD, Brancati FL, and Clark JM (2009) The association of obesity and cervical cancer screening: a systematic review and meta-analysis. Obesity (Silver Spring) 17: $375-81$ oby 2008480 [pii]

10.1038/oby.2008.480. 
16. Betancourt JR, Green AR, Carrillo JE, and Ananeh-Firempong O, 2nd (2003) Defining cultural competence: a practical framework for addressing racial/ethnic disparities in health and health care. Public Health Rep 118: 293-302 10.1093/phr/118.4.293.

17. Cognet M, Hamel C, and Moisy M (2012) [Health of migrants in France: effect of origin and sex-related discriminations] [French]. Revue Eur Migrations Int 28: 11-34

18. Zins $M$ and Goldberg M (2015) The French CONSTANCES population-based cohort: design, inclusion and follow-up. Eur J Epidemiol 30: 1317-28 10.1007/s10654-015-0096-4.

19. Haute Autorité de Santé, Dépistage er prévention du cancer du col de l'utérus. Actualisation du référentiel de pratiques de l'examen périodique de santé. 2013, Haute Autorité de Santé: Saint-Denis.

20. Knol MJ, Le Cessie S, Algra A, Vandenbroucke JP, and Groenwold RH (2012) Overestimation of risk ratios by odds ratios in trials and cohort studies: alternatives to logistic regression. Cmaj 184: 895-9 10.1503/cmaj.101715.

21. Zou $G$ (2004) A modified poisson regression approach to prospective studies with binary data. Am J Epidemiol 159: 702-6

22. Baron RM and Kenny DA (1986) The moderator-mediator variable distinction in social psychological research: conceptual, strategic, and statistical considerations. J Pers Soc Psychol 51: 1173-82

23. White IR, Royston P, and Wood AM (2011) Multiple imputation using chained equations: Issues and guidance for practice. Stat Med 30: 377-99 10.1002/sim.4067.

24. Sterne JA, White IR, Carlin JB, et al (2009) Multiple imputation for missing data in epidemiological and clinical research: potential and pitfalls. Bmj 338: b2393

25. von Hippel P (2007) Regression with missing Y's: an improved strategy for analyzing multiply imputed data. Sociol Methodol 37

26. Niedhammer I, Bugel I, Bonenfant S, Goldberg M, and Leclerc A (2000) Validity of selfreported weight and height in the French GAZEL cohort. Int J Obes Relat Metab Disord 24: $1111-8$

27. Beck F and Gautier A, Baromètre cancer 2010 [Cancer Barometer 2010]. 2012, Saint-Denis: Inpes.

28. Menvielle G, Dugas J, Richard JB, and Luce D (2017 epub) Socioeconomic and healthcare userelated determinants of cervical, breast and colorectal cancer screening practice in the French West Indies. Eur I Cancer Prev

29. Rauscher GH, Johnson TP, Cho YI, and Walk JA (2008) Accuracy of self-reported cancerscreening histories: a meta-analysis. Cancer Epidemiol Biomarkers Prev 17: 748-57 10.1158/1055-9965.epi-07-2629.

30. Howard M, Agarwal G, and Lytwyn A (2009) Accuracy of self-reports of Pap and mammography screening compared to medical record: a meta-analysis. Cancer Causes Control 20: 1-13 10.1007/s10552-008-9228-4.

31. Lofters AK, Moineddin R, Hwang SW, and Glazier RH (2013) Does social disadvantage affect the validity of self-report for cervical cancer screening? Int J Womens Health 5: 29-33 10.2147/ijwh.s39556.

32. ObEpi, Enquête épidémiologique nationale sur le surpoids et l'obésité. 2012, Inserm.

33. Brutel C (2017) [Born in France with at least one parent of foreign origin] [French]. Insee Première 1634

34. Mainguené A (2013) [Who are people who obtained the French nationality?] [French]. Infos migrations 47

35. Brutel C. [French, foreign and naturalized population in France since 2006] [French] https://www.insee.fr/fr/statistiques/1410693. 2015 [cited 2018 03/08].

36. Carrasquillo $O$ and Pati $S$ (2004) The role of health insurance on Pap smear and mammography utilization by immigrants living in the United States. Prev Med 39: 943-50 10.1016/j.ypmed.2004.03.033. 
37. Kim K and Han HR (2016) Potential links between health literacy and cervical cancer screening behaviors: a systematic review. Psychooncology 25: 122-30 10.1002/pon.3883.

38. Idehen EE, Korhonen T, Castaneda A, et al (2017) Factors associated with cervical cancer screening participation among immigrants of Russian, Somali and Kurdish origin: a population-based study in Finland. BMC Womens Health 17: 19 10.1186/s12905-017-0375-1.

39. Lindau ST, Tomori C, Lyons T, Langseth L, Bennett CL, and Garcia P (2002) The association of health literacy with cervical cancer prevention knowledge and health behaviors in a multiethnic cohort of women. Am J Obstet Gynecol 186: 938-43

40. Scheppers E, van Dongen E, Dekker J, Geertzen J, and Dekker J (2006) Potential barriers to the use of health services among ethnic minorities: a review. Family Practice 23 